\title{
A retrospective review of CyberKnife stereotactic body radiotherapy for adrenal tumors (primary and metastatic): Winthrop University Hospital experience
}

\author{
Amishi Desai ${ }^{*}$, Hema Rai, Jonathan Haas, Matthew Witten, Seth Blacksburg and \\ Jeffrey G. Schneider
}

Department of Hematology and Oncology, Winthrop University Hospital, Mineola, NY, USA

OPEN ACCESS

Edited by:

Dwight E. Heron,

University of Pittsburgh Cancer

Institute, USA

Reviewed by:

Heath Brandon Mackley,

Penn State Hershey Cancer Institute,

Sean P. Collins,

USA

Georgetown University Hospital, USA

${ }^{*}$ Correspondence: Amishi Desai,

Department of Hematology and Oncology, Winthrop University

Hospital, 200 Old Country Road,

Suite 440, Mineola, NY 11501, USA amishi198@gmail.com

Specialty section: This article was submitted to Radiation Oncology, a section of the journal Frontiers in Oncology

Received: 10 April 2015 Accepted: 03 August 2015 Published: 17 August 2015

Citation:

Desai A, Rai H, Haas J, Witten M, Blacksburg S and Schneider JG (2015) A retrospective review of

CyberKnife stereotactic body radiotherapy for adrenal tumors (primary and metastatic): Winthrop

University Hospital experience. Front. Oncol. 5:185.

doi: 10.3389/fonc.2015.00185
The adrenal gland is a common site of cancer metastasis. Surgery remains a mainstay of treatment for solitary adrenal metastasis. For patients who cannot undergo surgery, radiation is an alternative option. Stereotactic body radiotherapy (SBRT) is an ablative treatment option allowing larger doses to be delivered over a shorter period of time. In this study, we report on our experience with the use of SBRT to treat adrenal metastases using CyberKnife technology. We retrospectively reviewed the Winthrop University radiation oncology data base to identify 14 patients for whom SBRT was administered to treat malignant adrenal disease. Of the factors examined, the biological equivalent dose (BED) of radiation delivered was found to be the most important predictor of local adrenal tumor control. We conclude that CyberKnife-based SBRT is a safe, non-invasive modality that has broadened the therapeutic options for the treatment of isolated adrenal metastases.

Keywords: CyberKnife, adrenal glands, SBRT, metastasis, BED

\section{Introduction}

The adrenal gland is a common site of cancer metastasis. In an autopsy series involving 91 patients with metastatic cancer, metastatic spread to the adrenal gland was demonstrated in $30 \%$ of patients (1). This propensity for adrenal metastasis, exhibited by many different primary tumor types, is likely a consequence of the adrenal glands' rich sinusoidal blood supply (2). Lung cancer, the most prevalent form of metastatic cancer, is the most common primary tumor type responsible for adrenal metastases $(1,3)$. The majority of adrenal metastases are accounted for by lung (35\%), gastric (14\%), esophageal (12\%), and hepatobiliary (10\%) primary carcinomas (3).

The adrenal gland is made up of adrenal cortex and medulla. The adrenal cortex consists of the zona glomerulosa, which secretes mineralocorticoids (aldosterone), which regulate sodium and potassium homeostasis. The zona fasciculata secretes glucocorticoids (most importantly, cortisol). The zona reticularis secretes sex steroids (primarily androgens). The adrenal medulla synthesizes and secretes catecholamines, which modulate the body's sympathetic response to stress. The symptoms and signs of adrenal insufficiency depend upon the rate and extent of loss of adrenal function, whether mineralocorticoid production is preserved, and the degree of stress. The onset of adrenal insufficiency is often very gradual and it may go undetected until an illness or other stress precipitates adrenal crisis. 
Clinical manifestations of adrenal insufficiency include weakness, fatigue, anorexia, nausea, vomiting, constipation, hyperpigmentation, hypotension, vitiligo, electrolyte disturbances (hyponatremia, hyperkalemia, hypercalcemia), azotemia, anemia, and eosinophilia. In severe cases, it can lead to shock and death.

Even though surgery still remains a curative option for isolated adrenal metastasis, it can have its own complications like longer hospital stay, perioperative complications, and adrenal insufficiency.

Adrenal gland is located near critical organs, such as stomach, duodenum, small and large bowels, kidneys, spinal cord, liver, one should take into consideration tolerance of these organs in the treatment of adrenal tumors. Rigorous accounting of organ motion is also mandatory to ensure accurate radiotherapy of the adrenal gland. Adrenal function preservation is an added benefit of stereotactic body radiotherapy (SBRT) when compared to surgery.

With modern imaging technologies, the adrenal gland is often found to be a solitary site of metastatic disease. In such cases, surgical resection has often been pursued as definitive therapy. As reported by Lo et al., curative resection of solitary adrenal metastases resulted in overall survival rates of $73 \%$ at 1 year and $40 \%$ at 2 years (4). Focusing exclusively on non-small cell lung cancer (NSCLC) with solitary adrenal metastases, Tanvetyanon et al. demonstrated 5-year survival rates of $25 \%$ following resection of isolated synchronous adrenal metastases and $26 \%$ after resection of metachronous adrenal metastases (5). Complication rates ranging from 9 to $20 \%$ have been observed in series of patients reported to have undergone adrenalectomy in the management of solitary adrenal metastasis (6-13).

Conventional external beam radiotherapy has been considered an unreliable alternative to surgical resection for the definitive management of solitary adrenal metastases because treatment responses are typically transient and incomplete (6-20). In addition, conventional radiotherapy cannot compensate for tumor motion. In a study of 14 patients with adrenal metastases receiving radiation doses ranging from 16 to $60 \mathrm{~Gy}$, Soejima et al. reported a 6-month survival of 28.6 and $12.5 \%$ among the symptomatic group. Despite the poor response, conventional radiation may still prove efficacious for the palliation of pain related to adrenal metastasis (16). However, SBRT has more recently been introduced as a more reliable treatment for the control of the eradication of adrenal metastasis (12). It exploits the more potent radiobiological effect of hypofractionation, larger doses given over a shorter period of time. SBRT precision allows the delivery of ablative doses of radiation to tissue within the planning target volume with small margins to minimize the impact on normal tissue (19). At our institution, the CyberKnife, a robotic-based SBRT delivery system which accounts for intrafraction tumor motion, has been in use since $2005(19,20)$.

One of the advantages of the CyberKnife is the ability to continuously track, in real time the movement of a tumor or target with respiration. Katoh et al. (21) showed that adrenal tumors can move up to $6.1,11.1$, and $7.0 \mathrm{~mm}$ in the left-right, craniocaudal, and anterior-posterior directions, respectively. Given the doses used, and the sensitivity of the surrounding anatomy, having the ability to track a tumor that moves during respiration, such as an adrenal tumors or lung tumors is imperative in delivering an ablative dose of radiation without either missing the tumor or damaging surrounding anatomy. This study reports on our experience utilizing this technology to treat malignant adrenal disease.

\section{Materials and Methods}

\section{Study Design}

We utilized an Institutional Review Board approved database to retrospectively identify 14 patients for whom SBRT was administered to treat malignant adrenal disease from 2006 to 2011. Charts were reviewed to determine patient characteristics, treatment details, and outcomes. Primary study endpoints were treatment response, duration of response, and survival time measured from the initiation of SBRT. Treatment response was assessed on the basis of routine follow-up imaging studies with CT or PET/CT scan. Local treatment failure was defined as any radiographic progression of adrenal tumor. Distant failure was defined as the development of new metastases or progression of untreated metastases. All patients were treated with SBRT delivered via CyberKnife (Accuray Corporation; Sunnyvale, CA, USA) technology.

All tumors were treated using a CyberKnife robotic linear accelerator. All patients were immobilized using a thermoplastic cast with arms up. One fiducial marker was placed at least 5 days prior under CT guidance by an Interventional Radiologist to account for seed migration. CT imaging was performed using $1.5 \mathrm{~mm}$ cuts with and without contrast. At this institution, which as per NCCN guidelines regarding the use of hypofractionated SBRT has appropriate technology, physics, and clinical expertise, all treatments have been given safely and without difficulty. It is important, however, that this expertise be readily available at all times regarding the delivery of this form of treatment given the complexity involved.

Planning was performed using Multiplan (Accuray, Inc., Sunnyvale, CA, USA) inverse planning and delivered using the CyberKnife (Accuray, Inc.) with motion and respiratory tracking performed using the Synchrony system (Accuray, Inc.) Only the adrenal tumor was treated rather than the whole gland (Figure 1).

\section{Results}

\section{Patient Characteristics}

Patient and tumor characteristics are summarized in Table $\mathbf{1}$. Median age was 65 years (range, 49-91 years). Primary tumor sites included non-small cell lung $(n=6)$, renal cell $(n=2)$, melanoma $(n=1)$, primary adrenal $(n=1)$, mixed Mullerian $(n=1)$, GE junction $(n=1)$, bladder $(n=1)$, and lymphoma $(n=1)$. Five patients were found to have adrenal involvement at their original cancer diagnosis. For the nine remaining patients, the median interval from first cancer diagnosis to the clinical detection of adrenal metastasis was 14 months (range 8-56). Two patients had pain associated with adrenal metastases in the setting of widespread metastatic disease and received SBRT with palliative intent. Their pain markedly improved after treatment. The other 12 patients had no other sites of active metastasis and received SBRT with definitive intent. These patients did not receive any concurrent chemotherapy while getting CyberKnife. 
TABLE 1 | Patient characteristics and outcome.

\begin{tabular}{|c|c|c|c|c|c|c|}
\hline Patient & Age & Gender & Primary tumor & Outcome post CK & Time to local failure (months) & Time from CK to death (months) \\
\hline 1 & 62 & $M$ & NSCLC & Stable & 7 & 11 \\
\hline 2 & 91 & $\mathrm{M}$ & $\mathrm{RCC}$ & Regression & +38 & NA (still alive) \\
\hline 3 & 64 & $M$ & NSCLC & Stable & 2 (until death) & 2 \\
\hline 4 & 49 & $\mathrm{~F}$ & NSCLC & Progression & 0 & NA (still alive) \\
\hline 5 & 59 & $M$ & NSCLC & Stable & 5 & 7 \\
\hline 6 & 63 & $\mathrm{M}$ & DLBCL & Complete response & +3 & NA (still alive) \\
\hline 7 & 68 & $\mathrm{M}$ & Melanoma & Regression & 4 (until death) & 4 \\
\hline 8 & 49 & $\mathrm{~F}$ & $\mathrm{RCC}$ & Regression & 14 (until death) & 14 \\
\hline 9 & 70 & $\mathrm{~F}$ & Adrenocortical carcinoma & Stable & 4 & 11 \\
\hline 10 & 66 & $\mathrm{~F}$ & MMT & NA & NA & 9 \\
\hline 11 & 75 & $\mathrm{~F}$ & NSCLC & NA & NA & 3 \\
\hline 12 & 71 & $\mathrm{M}$ & NSCLC & Progression & 0 & 3 \\
\hline 13 & 60 & $\mathrm{M}$ & GE junction adenocarcinoma & Regression & 11 (until death) & 11 \\
\hline 14 & 83 & $M$ & Urothelial carcinoma & NA & NA & 1 \\
\hline
\end{tabular}

CK, CyberKnife; NSCLC, non-small cell lung cancer; RCC, renal cell carcinoma; DLBCL, diffuse large B cell lymphoma; MMT, mixed Mullerian tumor; GE junction, gastroesophageal.

TABLE 2 | Delivered SBRT regimens and calculated BEDs.

\begin{tabular}{lrrrrr}
\hline Patient & Time & Dose (cGy) & \#fx & BED (cGy) & 180 cGy Eq \\
\hline 1 & 0 & 3000 & 3 & 6000 & 5085 \\
2 & 56 & 3000 & 3 & 6000 & 5085 \\
3 & 12 & 2750 & 5 & 4263 & 3612 \\
4 & 12 & 2500 & 5 & 3750 & 3178 \\
5 & 14 & 2100 & 3 & 3570 & 3025 \\
6 & 0 & 2500 & 5 & 3750 & 3178 \\
7 & 31 & 2400 & 3 & 4320 & 3661 \\
8 & 24 & 3000 & 3 & 6000 & 5085 \\
9 & 0 & 2000 & 5 & 2800 & 2373 \\
10 & 8 & 2500 & 5 & 3750 & 3178 \\
11 & 12 & 2400 & 3 & 4320 & 3661 \\
12 & 13 & 2500 & 5 & 3750 & 3178 \\
13 & 16 & 2400 & 3 & 4320 & 3661 \\
14 & 19 & 1300 & 1 & 2990 & 2534 \\
\hline
\end{tabular}

\section{SBRT Treatment Plans and Delivered Biological Equivalent Doses}

Individualized SBRT treatment schedules and calculated biological equivalent dose (BED) are shown in Table 2. With the exception of 1 patient with primary bladder cancer receiving $1300 \mathrm{cGy}$ in a single treatment fraction, the remaining 13 patients received a total of either 3 or 5 fractions with each fraction ranging from 500 to $1000 \mathrm{cGy}$. This heterogeneity in treatment delivery led to a wide range of delivered BEDs (2990-6000 cGy), assuming an alpha/beta ratio of 10 .

\section{Local Adrenal Tumor Control}

There was considerable variation in calculated BEDs (range $4667-13,000 \mathrm{cGy})$. BED was the most important predictor of local adrenal tumor control. According to best adrenal tumor response, mean BEDs were $10,053 \mathrm{cGy}$ for radiographic regression of disease $(n=5) ; 8115 \mathrm{cGy}$ for stable disease $(n=4)$, and $6667 \mathrm{cGy}$ for progression of disease $(n=2), p=0.047$. No adrenal metastases resulting from a solid tumor responded to SBRT with $\mathrm{BED}<8800 \mathrm{cGy}$ and no patient experienced initial adrenal progression following SBRT with BED $>6667 \mathrm{cGy}$. Duration of adrenal tumor control also correlated with calculated mean BED, which was $9676 \mathrm{cGy}$ for never locally failing $(n=6)$ and $7600 \mathrm{cGy}$
TABLE 3 | Characteristics of previous studies using SBRT to treat adrenal metastases.

\begin{tabular}{|c|c|c|c|}
\hline $\begin{array}{c}\text { Reference/recruitment/ } \\
\text { country }\end{array}$ & $\begin{array}{c}\text { No. of } \\
\text { patients }\end{array}$ & $\begin{array}{l}\text { Radiation dose } \\
\text { (median) }\end{array}$ & $\begin{array}{c}\text { Outcome } 1 \text { year } \\
\text { OS, LC, DC }\end{array}$ \\
\hline $\begin{array}{l}\text { Chawla et al. } \\
(23) / 2001-2007 / \text { USA }\end{array}$ & 30 & 400 cGy $\times 10$ fx & $\begin{array}{l}44 \% \\
55 \% \\
13 \%\end{array}$ \\
\hline $\begin{array}{l}\text { Katoh et al.* } \\
(21) / 2004-2006 / \text { Japan }\end{array}$ & 9 & $600 \mathrm{cGy} \times 8 \mathrm{fx}$ & $\begin{array}{c}78 \% \\
100 \%\end{array}$ \\
\hline $\begin{array}{l}\text { Casamassima et al. } \\
\text { (22)/2002-2009/Italy }\end{array}$ & 48 & 1200 cGy × $3 \mathrm{fx}$ & $\begin{array}{c}39.7 \% \\
90 \% \\
9 \%\end{array}$ \\
\hline $\begin{array}{l}\text { Holy et al. } \\
\text { (26)/2002-2009/Germany }\end{array}$ & 18 & $720 c G y \times 5 f x$ & $\begin{array}{c}23 \text { months } \\
77 \%\end{array}$ \\
\hline $\begin{array}{l}\text { Torok et al. } \\
(27) / 2002-2009 / \text { USA }\end{array}$ & 7 & $\begin{array}{l}1700 \text { cGy in } 1 \mathrm{fx} \\
(1600 \text { cGy in } 1 \mathrm{fx} \text { and } \\
2700 \text { cGy in } 3 \mathrm{fx})\end{array}$ & $\begin{array}{c}8 \text { months } \\
63 \%\end{array}$ \\
\hline
\end{tabular}

*Katoh reference above includes patients with primary adrenal tumors and metastases.

for ever locally failing tumors $(n=5)$. However, eventual local treatment failure was seen in one of three patients receiving even the highest calculated BED (13,000 cGy).

\section{Toxicity}

No patient developed renal or adrenal insufficiency and there were no bowel or spinal cord injuries.

\section{Literature Review}

Several groups have previously reported on their experiences with SBRT for the definitive treatment of adrenal oligometastases with conflicting results as summarized in Table 3. For example, Casamassima et al. at the University of Florence reported an impressive $90 \%$ local control rate at 2 years (22), whereas Chawla et al. at the University of Rochester reported only a $55 \% 1$ year local control rate (23). These differences may be explained by differences in SBRT dosing and fractionation accounting for significant differences in the prescribed BEDs with maximum delivered BED of $13,730 \mathrm{cGy}$ ( $36 \mathrm{~Gy}$ in 3 fractions) in the Florence series, but just between $2240 \mathrm{cGy}$ (16 Gy in 4 fractions) and $7500 \mathrm{cGy}$ (50 Gy in 10 fractions) in the Rochester cohort (22). Other series have 


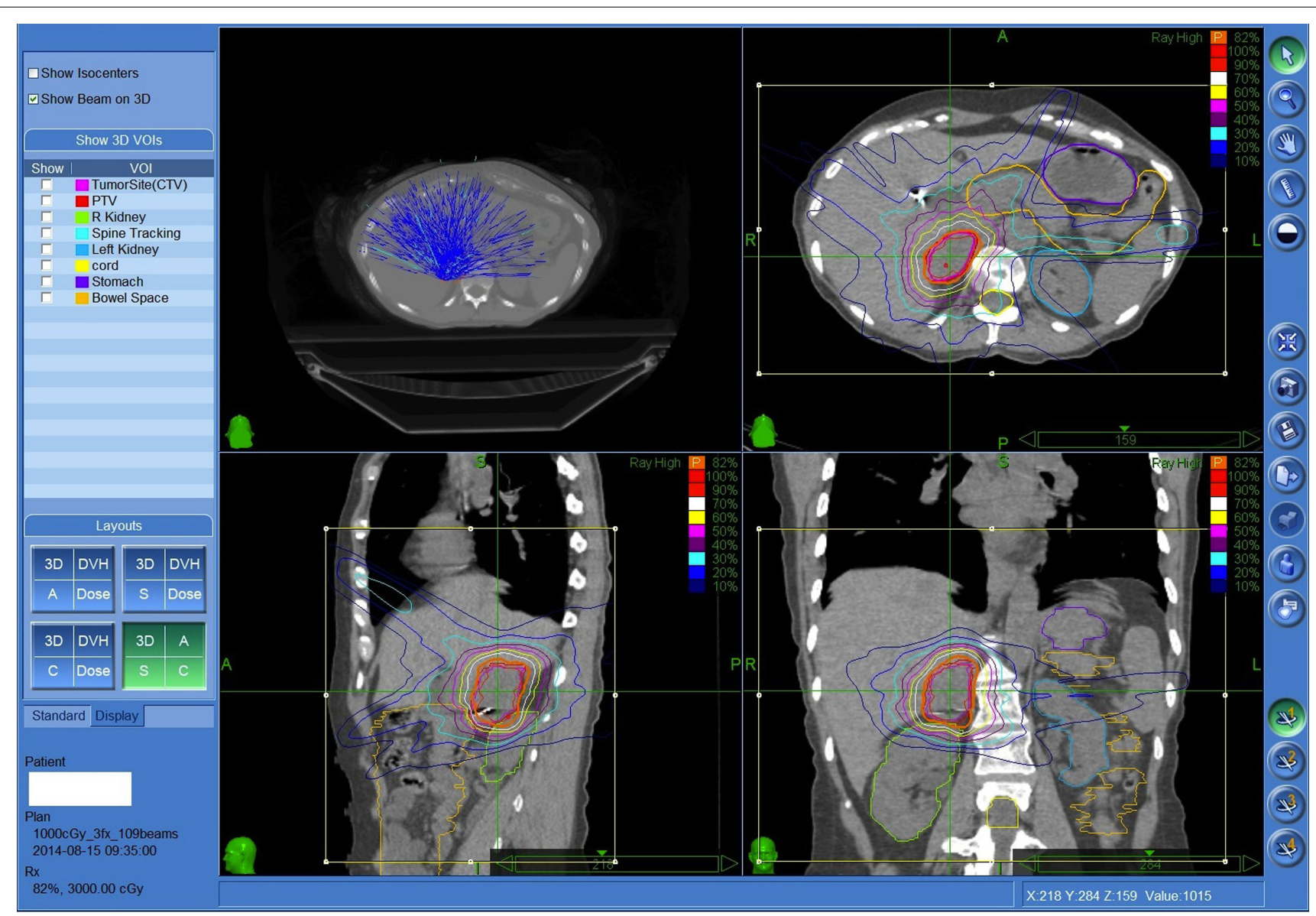

FIGURE 1 | Fifty-seven-year-old female with metastatic small cell lung cancer with limited biopsy proven painful recurrence in the right adrenal gland despite prior systemic therapy. Patient was treated to the right adrenal metastasis 3000 cGy in three fractions prescribed to the $82 \%$ isodose line. Both kidneys, spinal cord, and regional bowel were contoured. suggested that BEDs $>10,000 \mathrm{cGy}$ are required to achieve optimal local control $(24,25)$.

In a series from Hokkaido University, 9 patients with 10 adrenal lesions were treated with SBRT with a dose of 4800 cGy in 8 fractions. The 1-year overall survival and local control rates were 78 and $100 \%$, respectively (21). In contrast to the other groups, they included primary adrenal tumors and perirenal metastatic lymph nodes. In another study by Holy et al., 18 patients with NSCLC and adrenal metastases treated with definitive SBRT for adrenal metastases from NSCLC, experienced a median progression free survival (PFS) of 4.2 months. PFS was markedly increased to 12 months for 13 patients with isolated adrenal metastases. After a median follow-up of 21 months, 10 of these 13 patients achieved local control and median overall survival was 23 months (26). These results compare favorably to the surgical series of Porte et al. where surgical resection of solitary adrenal metastasis was reported to achieve a median PFS of just 13 months (28).

\section{Discussion}

Historically, surgery has been the mainstay of treatment for isolated adrenal metastases. In 1982, Twomey et al. documented prolonged survival following adrenalectomy in the management of oligometastatic NSCLC (29). Patients with a synchronous metastasis who underwent adrenalectomy had a shorter overall survival than those with metachronous metastasis. Overall, subsequent long-term disease free survival has been observed in approximately $25 \%$ of patients undergoing resection of solitary adrenal metastasis (6). Long-term survival after resection of isolated NSCLC adrenal metastases was also demonstrated by Mercier et al. with an overall 5-year survival rate of 23.3 and $38 \%$ if the isolated adrenal metastasis occurred 6 months after lung resection (11). In colorectal carcinoma, Katayama et al. reported 5 of 11 patients with adrenal metastases remained alive without signs of recurrence after adrenalectomy with follow-up times ranging from 8 months to 9 years (30). In renal cell carcinoma, patients with solitary adrenal metastases achieved a significant tumor specific survival benefit with a median survival of 68 months compared to patients with additional metastatic sites at the time of surgery (31).

In this report, we have retrospectively reviewed our institutional database to identify 14 patients for whom SBRT was administered to treat malignant adrenal disease from 2006 to 2011. Of the factors examined, BED was the most important predictor 
of local adrenal tumor control. The duration of adrenal tumor control correlated with calculated mean BED, which was $7600 \mathrm{cGy}$ for local failures vs. $9676 \mathrm{cGy}$ for those who attained local control. This finding is supported by other series, which have suggested the delivery of BEDs $>10,000$ cGy to achieve optimal tumor control $(24,25)$. Our experience with patients treated above and below this threshold (median BED of $8460 \mathrm{cGy}$ ) also supports the 10,000 cGy threshold.

We observed an initial tumor control rate of $64 \%$ (36\% tumor regression plus $28 \%$ stable disease) similar to the $78 \%$ (22\% regression plus $56 \%$ stable disease) adrenal tumor control rate reported by Torok et al. (27). These small differences could be explained by different tumor types in these two reports. Notably, our series comprises an admixture of different primary tumor types, whereas Torok et al. included only lung and hepatocellular primary carcinomas. In our series, all patients with stable disease following CyberKnife treatment had primary lung cancers. Notably, Torok et al. study population predominantly comprised patients with lung primaries; this could explain the discrepancy in their higher initial response and difference in patients with stable disease. The transient nature of prolonged control from metastatic lung primaries was demonstrated in both studies.

In addition, we also looked at tumor histology as it predicted for treatment outcome. We had an admixture of different

\section{References}

1. Belleggia C, Piga A, Torresi U, Montironi R, Cellerino R. Adrenal metastasis: clinical and pathological aspects. Minerva Med (1888) 19:1-4.

2. Kung AW, Pun KK, Lam K, Wang C, Leung CY. Addisonian crisis as presenting feature in malignancies. Cancer (1990) 65:177-9. doi:10.1002/10970142(19900101)65:1<177::AID-CNCR2820650134>3.0.CO;2-8

3. Lam KY, Lo CY. Metastatic tumors of the adrenal glands: a 30 year experience in a teaching hospital. Clin Endocrinol (Oxf) (2002) 56:95-101. doi:10.1046/j. 0300-0664.2001.01435.x

4. Lo CY, van Heerden JA, Soreide JA, Grant CS, Thompson GB, Lloyd RV, et al. Adrenelectomy for metastatic disease to the adrenal glands. Br J Surg (1996) 83:528-31. doi:10.1002/bjs.1800830432

5. Tanvetyanon T, Robinson LA, Schell MJ, Strong VE, Kapoor R, Coit DG, et al. Outcomes of adrenalectomy for isolated synchronous versus metachronous adrenal metastases in non small cell lung cancer. A systematic review and pooled analysis. J Clin Oncol (2008) 26:1142-7. doi:10.1200/JCO.2007.14. 2091

6. Kim SH, Brennan MF, Russo P, Burt ME, Coit DG. The role of surgery in the treatment of clinically isolated adrenal metastasis. Cancer (1998) 82:389-94. doi:10.1002/(SICI)1097-0142(19980115)82:2<395::AID-CNCR20> 3.3. $\mathrm{CO} ; 2-\mathrm{E}$

7. Castillo OA, Vitagliano G, Kerkebe M, Parma P, Pinto I, Diaz M. Laparoscopic adrenalectomy for suspected metastasis of adrenal glands: our experience. Urology (2007) 69:637-41. doi:10.1016/j.urology.2006.12.025

8. Higashiyama M, Doi O, Kodama K, Yokouchi H, Imaoka S, Koyama H. Surgical treatment of adrenal metastasis following pulmonary resection for lung cancer: comparison of adrenalectomy with palliative therapy. Int Surg (1994) 79: 124-9.

9. Kebebew E, Siperstein AE, Clark OH, Duh QY. Results of laparoscopic adrenalectomy for suspected and unsuspected malignant adrenal neoplasms. Arch Surg (2002) 137:948-51. doi:10.1001/archsurg.137.8.948

10. Mercier O, Fadel E, de Perrot M, Mussot S, Stella F, Chapelier A, et al. Surgical treatment of solitary adrenal metastasis from non small cell lung cancer. J Thorac Cardiovasc Surg (2005) 130:136-40. doi:10.1016/j.jtcvs.2004. 09.020

11. Moinzadeh A, Gill IS. Laparoscopic radical adrenalectomy for malignancy in 31 patients. J Urol (2005) 173:519-25. doi:10.1097/01.ju.0000149038.89467.30 primaries, but the majority was six patients with NSCLC: four adenocarcinoma, one squamous cell carcinoma, and one highgrade sarcoma. The latter two patients progressed after treatment, which could be attributable to aggressive histology. The three adenocarcinomas remained stable with two eventually progressing locally at 5 and 7 months and one remained stable until failing distantly at 2 months. The fourth patient opted for palliative care, so no post treatment scans were obtained. Other primaries fared better with regression in the size of the lesion noted in renal carcinoma, GE junction adenocarcinoma, and melanoma. Three of these patients eventually succumbed to their disease from distant failure. Complete response was documented for diffuse large B cell lymphoma.

While surgical resection remains a suitable option for patients with isolated adrenal metastases who are able to undergo that approach, CyberKnife-based SBRT is a safe, non-invasive alternative modality that has broadened the therapeutic options for the attainment of palliation and local control of this historically difficult-to-manage patient cohort. When utilized in this setting, we recommend targeting a BED of at least 10,000 cGy. We also encourage consideration of this approach in all patients with solitary adrenal metastasis who cannot or will not undergo surgical resection. Larger series and increased follow-up times will be required in the future evaluation of this treatment.

12. Sarela AI, Murphy I, Coit DG, Conlon KC. Metastasis to the adrenal gland: the emerging role laparoscopic surgery. Ann Surg Oncol (2003) 10:1191-6. doi:10.1245/ASO.2003.04.020

13. Sebag F, Calzolari F, Harding J, Sierra M, Palazzo FF, Henry JF. Isolated adrenal metastasis: the role of laparoscopic surgery. World J Surg (2006) 30:888-92. doi:10.1007/s00268-005-0342-0

14. Soffen EM, Solin LJ, Rubenstein JH, Hanks GE. Palliative radiotherapy for symptomatic adrenal metastases. Cancer (1990) 65:1318-20. doi:10.1002/10970142(19900315)65:6<1318::AID-CNCR2820650611>3.0.CO;2-H

15. Short S, Chaturvedi A, Leslie MD. Palliation of symptomatic adrenal gland metastases by radiotherapy. Clin Oncol (R Coll Radiol) (1996) 8:387-9. doi:10. 1016/S0936-6555(96)80087-2

16. Soejima T, Hirota S, Hishikawa Y, Hamanaka A, Ozawa Z, Endo M, et al. [Radiation therapy for adrenal metastases.]. Nippon Igaku Hoshasen Gakkai Zasshi (1997) 57:801-4.

17. Miyaji N, Miki T, Itoh Y, Shimada J, Takeshita T, Churei H, et al. Radiotherapy for adrenal gland metastasis from lung cancer: report of three cases. Radiat Med (1999) 17:71-5.

18. Zeng ZC, Tang ZY, Fan J, Zhou J, Qin LX, Ye SL, et al. Radiation therapy for adrenal gland metastases fro hepatocellular carcinoma. Jpn J Clin Oncol (2005) 35:61-7. doi:10.1093/jjco/hyi020

19. Martin A, Gaya A. Stereotactic body radiotherapy: a review. Clin Oncol (2010) 22:157-72. doi:10.1016/j.clon.2009.12.003

20. Dieterich S, Gibbs IC. The CyberKnife in clinical use: current roles, future expectations. Front Radiat Ther Oncol (2011) 43:181-94. doi:10.1159/ 000322423

21. Katoh N, Onimaru R, Sakuhara Y, Abo D, Shimizu S, Taguchi H, et al. Real time tumor tracking radiotherapy for adrenal tumors. Radiother Oncol (2008) 87:418-24. doi:10.1016/j.radonc.2008.03.013

22. Casamassima F, Livi L, Masciullo S, Menichelli C, Masi L, Meattini I, et al Stereotactic radiotherapy for adrenal gland metastases: University of Florence experience. Int J Radiat Oncol Biol Phys (2012) 82:919-23. doi:10.1016/j.ijrobp. 2010.11.060

23. Chawla S, Chen Y, Katz AW, Muhs AG, Philip A, Okunieff P, et al. Stereotactic body radiotherapy for treatment of adrenal metastases. Int J Radiat Oncol Biol Phys (2009) 75:71-5. doi:10.1016/j.ijrobp.2008.10.079

24. Onishi H, Shirato H, Nagata Y, Hiraoka M, Fujino M, Gomi K, et al. Hypofractionated stereotactic radiotherapy (HypoFXSRT) for stage I non small cell lung 
cancer: updated results of 257 patients in a Japanese multi-institutional study. J Thorac Oncol (2007) 2:S94-100. doi:10.1097/JTO.0b013e318074de34

25. Onishi H, Shirato H, Nagata Y, Hiraoka M, Fujino M, Gomi K, et al. Stereotactic body radiotherapy (SBRT) for operable stage I non small cell lung cancer: can SBRT be comparable to surgery? Int J Radiat Oncol Biol Phys (2011) 81:1352-8. doi:10.1016/j.ijrobp.2009.07.1751

26. Holy R, Piroth M, Pinkawa M, Eble MJ. Stereotactic body radiation therapy (SBRT) for treatment of adrenal gland metastases from non-small cell lung cancer. Strahlenther Onkol (2011) 184:245-51. doi:10.1007/s00066-011-2192-z

27. Torok J, Wegner RE, Burton SA, Heron DE. Stereotactic body radiation therapy for adrenal metastases: a retrospective review of a noninvasive therapeutic strategy. Future Oncol (2011) 7:145-51. doi:10.2217/fon.10.165

28. Porte HL, Roumilhac D, Graziana JP, Eraldi L, Cordonier C, Puech P, et al. Adrenalectomy for a solitary adrenal metastasis from lung cancer. Ann Thorac Surg (1998) 65:331-5. doi:10.1016/S0003-4975(97)01284-8

29. Twomey P, Montgomery C, Clark O. Successful treatment of adrenal metastases from large cell carcinoma of the lung. JAMA (1982) 248:581-3. doi:10.1001/ jama.248.5.581
30. Katayama A, Mafune K, Makuuchi M. Adrenalectomy for solitary adrenal metastasis from colorectal carcinoma. Jpn J Clin Oncol (2000) 30:414-6. doi: 10.1093/jjco/hyd104

31. Siemer S, Lehmann J, Kamradt J, Loch T, Remberger K, Humke U, et al. Adrenal metastases in 1635 patients with renal cell carcinoma: outcome and indication for adrenalectomy. J Urol (2004) 171:2155-9. doi:10.1097/01.ju.0000125340. 84492.a7

Conflict of Interest Statement: The authors declare that the research was conducted in the absence of any commercial or financial relationships that could be construed as a potential conflict of interest.

Copyright (C) 2015 Desai, Rai, Haas, Witten, Blacksburg and Schneider. This is an open-access article distributed under the terms of the Creative Commons Attribution License (CC BY). The use, distribution or reproduction in other forums is permitted, provided the original author(s) or licensor are credited and that the original publication in this journal is cited, in accordance with accepted academic practice. No use, distribution or reproduction is permitted which does not comply with these terms. 